\title{
Construction and Practice of Animation Talent Cultivation Mode
}

\author{
Zhanji Gui ${ }^{1}$, Keliang Zhang ${ }^{2^{*}}$ and Yingbin Fu \\ Hainan College of Software Technology \\ 59637216@qq.com \\ *The corresponding author
}

Keywords: Animation major; Animation film; Mode; Cultivation mode; Master studios

\begin{abstract}
This paper constructs the cultivation mode for talents specialized in animation, on the basis of characteristics of vocational major of animation production and design. Its basic concept is to divide the production and manufacturing of an animation film into multiple steps by following the main line as commercial animation production, via the analysis on the process of animation production together with great masters and industrial experts. The aim is to allow students to master one step of animation production through studying one knowledge module constructed based on the steps gradually master the entire process of animation production according to the knowledge modules with increasing difficulty corresponding to related steps. Meanwhile, master studios have carried out a three-level modern apprenticeship for students with pay to build up a world-class set of scientific and effective cultivation mode for students in higher vocational and professional colleges, featuring significant practice effect.
\end{abstract}

\section{Introduction}

Since the year 2004, China's government has promoted a series of policies to support animation industry in succession and built up "National Revitalization Base of Animation and Game Industry" in several cities nationwide. With national policy promotion, attention of all walks of life and industrial efforts, animation industry has enjoyed the prosperous development at a moment, with various cities establishing animation industry bases, holding animation exhibitions and producing animation works. After undergoing over a decade of growth, China's animation industry today is to be influential and flourishing.

However, the rapid development of animation industry is not matched by the satisfactory talent cultivation. Several problems exist in the cultivation of vocational talents majored in animation production and design. The first one shall be disconnection between students' academic mastery and industrial demand. The second one shall be the aimlessness of animation education, indicating that the objective of talent cultivation is not set according to the demands of animation talent in the current market, which has led to the difficult professional development for animation education, influencing on the efficiency of animation education [1]. The third one shall be the severe disjunction between current teaching materials and practice for animation major, featuring by the old and simple cases that are basically episodic in lack of integrality to link all of chapters to demonstrate the creative process of animation without pertinence and pragmaticality. The fourth one shall be the narrowness of education guideline. Creation dominates the animation works, yet most of vocational colleges put blind emphasis on software instruction instead of the cultivation of animation creation, resulting in students' poor quality in humanity and art. In accordance with the problems mentioned above, we construct a module talent cultivation mode that is oriented by animation production and integrates industry and education, under masters' instruction.

\section{Establishment of Talent Cultivation Mode}

Establish a Module Course System of Industry-education Integration and Animation Production Orientation under Master Instruction. The concrete method is to hire masters with animation industries to establish four master studios: we hire three national second grade animation 
directors and one famous Canadian animation master as the specially-appointed professors of this college and establish their individual master studios.

They are responsible to instruct the establishment of talent cultivation mode for talents of animation design and production, from their own perspectives as industrial masters. After four years of reform and exploration, we have put promoting students' professional competiveness as the essence; followed the rules of career growth; uniformed the position requirements and education demands and integrated the enterprise culture and campus culture; combined the production and enterprise assessment with education through the creation and production of enterprises' animation projects, to implement the education mode integrating "education, study, practice, production, assessment and appreciation" together, based on "studios" as the carriers. We have constructed the module course system oriented by the production process of commercial animation. Its basic concept is to divide the production and manufacturing of an animation film into multiple steps by following the main line as commercial animation production, via the analysis on the process of animation production together with great masters and industrial experts. The aim is to allow students to master one step of animation production through studying one knowledge module constructed based on the steps gradually master the entire process of animation production according to the knowledge modules with increasing difficulty corresponding to related steps. We have built up a world-class set of scientific and effective cultivation mode for students in higher vocational and professional colleges with significant practice effect.

A series of HD 3D animation projects of CCTV have been introduced to the education, including Happy Puppy, Rubi and Gold Conch, for the purpose of involving students in the production of commercial animation during the process of their professional study for the comprehensive promotion of their professional quality, specialty skill and innovation capability. Through the planning and production of several HD animation projects featured by Hainan local characteristics including The Legend of Stone Tiger, The Story of Bangxi Village and Li Nationality's Double Third Day, we have encouraged students' active innovation, in order to cultivate the innovation capability of animation talents.

Students' participation in commercial animation production has comprehensively promoted their professional quality, specialty skills and innovation capability. During the process of education reform, we have insisted in the projectization of education contents, professionalization of teaching methods, real scene of teaching environment, productization of teaching results, procedural orientation of process management and enterprization of organization management.

\section{Implementation of Three-level Apprenticeship}

Master Guidance. In the three-level apprenticeship, masters shall not only provide advices for the construction of course system from the perspectives of industrial and enterprise masters, but also take advantage of the studios strategically as the platform by working as the chief planners and leaders of commercial animations produced by their studios in the practice steps, under the guidance of animation project production.

Mentor Responsibility System. Mentors as teachers of animation specialty with this college as well as part-time teachers from related enterprises are appointed to be responsible for the whole production process of animation projects, the daily work of studios and student management, instructed by respective masters.

Master's Instruction. Masters, consisted of technical backbones of our school-run enterprise, Hainan HNCST Animation Production Co., Ltd, are responsible of one step in the entire production process of an animation project respectively.

Each master's studio encourages students of different grades to establish multiple 20-member teams based on their own specialty characteristics. Each team of a studio shall have different posts or roles so that the studio's structure could meet the standard of an enterprise as much as possible.

Studios work as the platforms for masters to instruct their skills and experience to their apprentices. Students who join in the studios with outstanding skills will be employed by enterprises after experiencing real projects in studios and become new masters in the production 
lines, to realize the orientation by senior workers. This is to avoid the skill gap of students after graduation and to ensure the long-term effective operation of modern apprenticeship.

\section{Establishment of Industry-education-integrated Training Environment and Our Own School-run Enterprise}

HNCST (Hainan College of Software Technology) purchased an industry-university-research cooperation building in Hainan State-level Ecological Software Park covering an area over 2,000 square meters; established its own school-run enterprise, Hainan HNCST Animation Production Co., Ltd.; introduced Muda Animation Co., Ltd., Hainan Fenghua Animation Culture Development Co., Ltd. , Hainan Tumou Creative Planning Co., Ltd. and other enterprises to be stationed in the industry-university-research cooperation building for in-depth industry-education integration; and established two animation production lines. Meanwhile, HNCST has shaped up the new normal form for university-enterprise cooperation and enterprise-enterprise cooperation; and provided the support system for the concrete implementation and landing of animation-guided module talent cultivation mode with industry-university integration.

\section{Achievements}

During the past four years, HNCST students majored in animation have won a first prize in the animation contest item of 2014 National Vocational Colleges Professional Skill Competition; a second prize and third prize in the animation contest item of 2015 National Vocational Colleges Professional Skill Competition; a first prize in the animation contest item of 2016 National Vocational Colleges Professional Skill Competition; a gold award in the 1st Session of International Digital Arts Design Works Exhibition held in Barcelona in 2016.

In addition, HNCST has researched and developed a set of teaching materials suitable for the reform on animation specialty, which has mainly applied the original animation films created by HNCST animation school during the past years as the teaching materials, including Early-stage Creation of Original Animation Short Films, Scene Design of Original Animation Short Films, Character Design of Original Animation Short Films, Storyboard Design of Original Animation Short Films, Action Design of Original Animation Short Films and From Introduction to Proficiency-Real Book of MAYA 3D Animation Project. This set of teaching materials have been guided by the original animation projects during its early stage, middle stage and late stage, in order to involve the production process of animation into the teaching cases and break the original epidemic structure of teaching materials.

Furthermore, HNCST has produced 12 HD commercial animation films including The Little Train Choo Choo, Rubi and Gold Conch; undertaken the production of Happy Dog-Forest Adventure of CCTV Animation to complete the entire animation process including playwriting, character design, scene design, modeling, special effect design and so on, which have been highly praised by CCTV directors and this film has been broadcasted in CCTV Children's Channel.

NHCST has paid great attention to the production of its original animation films and has produced 15 short animation films featured by Hainan local characteristics, including The Red Detachment of Women, The Legend of Stone Tiger, Luhuitou-The Story of Bangxi and The Legend of Limushan; produced the animation film of Docking Mission of Shenzhou-8 and Tiangon-1 for CCTV; and created an online game The Legend of Hainan, receiving high evaluation from its customers and industrial insiders.

\section{Great Repercussion from the Society}

On Nov. 16th, 2016, the 1st Session of Hainan-Taiwan Forum on Higher Vocational Education was held in Haikou for the common discussion between Hainan and Taiwan for the prospective development of higher vocational education. Its subject host has given a plenary lecture on Practice and Exploration on Cultivation Mode for Vocational Animation Talents on invitation. At 2016 
Experience Exchange Meeting on Vocational College Reform Innovation, Connotation Enhancement and Quality Construction sponsored by Vocational and Technical Education Branch of China Education Society of Electronics, its subject host has given a speech of experience exchange themed Practice and Exploration on Cultivation Mode of Vocational Animation Talents. Participating leaders and representatives interested in the speech have visited the works exhibition of animation specialty of HNCST with great praise. The subject host has given a plenary session at 2016 annual meeting of Hainan Provincial Computer Forum and Hainan Provincial Computer Society, themed Practice and Exploration on Cultivation Mode of Vocational Animation Talents.

China Education Daily and Spiritual Civilization News have reported parts of its research results in animation education Hainan Daily and South China Metropolitan Post have reported its research results in animation education for 7 times; Xinhua News Agency for Senior Executives Only has reported parts of its research results.

\section{References}

[1] Ye Yuwen. Teaching Reform Strategy of Animation Specialty from the Perspective of Animation Industry Development [J]. Yalujiang Literature Monthly, 2015, (11) :132.

[2] He Hui, Huang Baiqing. A Rustic Opinion on Basic Theory Education in China [J]. Art Research, 2012, (4) 77-80.

[3] Wang Ruyi, Mo Xinping. Application and Exploration of "Celebrity Studio" Talent Cultivation Mode in Animation Design and Production Specialty Education [J]. China Adult Education 2015, (9): 140-142.

[4] Ning Xiang. A Discussion on Education Reform of Vocational Animation Specialty [J]. Art and Design, 2009, (5): 137-138.

[5] Gao Yong, Research on the innovation mode of practical teaching of art design specialty in Colleges and Universities [J]. Education modernization, 2016, (2): 14-16.

[6] Yan Qifeng, Research on the innovation of talent training mode of art design specialty based on practice teaching $[\mathrm{J}]$. Northwest Art, 2016, (3): 53-55.

[7] Jia Xukun, Gao Da, Discussion on the teaching practice of art design specialty in Colleges and Universities [J]. Contemporary educational practice and teaching research, 2015, (5): 212.

[8] Chen Shuai, Huang Chunhua, The basic idea of cultivating the innovative talents of art design under the school enterprise combination [J]. Innovation and Entrepreneurship Education, 2013, (6): 61-63.

[9] Pan $\mathrm{Yu}, \mathrm{A}$ study on the training mode of the cooperation of production, study and research in art design specialty in local colleges and Universities [J]. Art Education Research, 2014, (9): 136-137.

[10] The teaching mode of "studio system" in animation design and production in Higher Vocational Colleges [J]. Chinese off campus education, 2011, (6): 138-139.

[11] Chen Ying, On the essential features and development of Vocational Education in Germany [M]. Shanghai SDX Joint Publishing Company, 2015, (5). 